\title{
Contrapuntal cosmopolitanism: distantiation as social relatedness among house-builders in Maputo, Mozambique
}

\begin{abstract}
This article explores forms of social relatedness among peri-urban residents in Maputo, Mozambique, which have as their premise that social interaction occurs in a world that is both unknown and potentially dangerous. As I show, reciprocal encounters are therefore based on creating distance rather than approximation. Although people acknowledge the crucial importance of social others, it is important to maintain appropriate distances in order to avoid awakening unwanted desires. I consequently introduce the notion of contrapuntal cosmopolitanism to designate the production of viable (reciprocal) distances in unfamiliar milieux peopled by important but also capricious others.
\end{abstract}

Key words governance, urban planning, relational ontology, failed state, Mozambique

\section{Introduction}

From the mid-18th-century Encyclopédie, we learn that a 'cosmopolitan' is 'a man without a fixed abode, or better, a man who is nowhere a stranger' (Diderot and d'Alembert 1751-65: 4, 297, in Cheah 2006: 487). Although this conceptualisation might indicate an equivalence to rootlessness, we should, Cheah tells us, rather imagine a form of belonging that 'involves the transcendence of the particularistic and blindly given ties of kinship and country' (2006: 487). In short, as a particular form of social sensibility, cosmopolitanism refers to, and here I cite Fardon, 'a capacity to reach beyond cultural difference' (2008: 238). Based on this initial reading, an imminent analytical task would obviously be to identify those cosmopolitan capacities that enable individual agents to rise, so to speak, above their 'proximal categorizations and identifications of nation, ethnicity, class, religion, gender, locale and so on' (Rapport 2006: 24). However, as an increasing number of people are cast in worlds that fundamentally lack a fit between the material interconnectedness brought about by intense global flows and the degree of formation of non-local solidarities, our objective might perhaps be phrased differently. Let me again return to Fardon, whose ethical considerations regarding the unstable political environment in Nigeria might serve our purpose here as well. Fardon thus asks, '[w] hen is it reasonable to anticipate people will embrace fallibism and pluralism? When, most basically, can they afford to do so?' (2008: 250, emphasis added). 
In this article, I wish to rehearse one analytical argument, which can be taken as a tentative response to Fardon's pertinent question. Based on prior and ongoing ethnographic research in peri-urban areas of Maputo, Mozambique, I shall explore forms of social relatedness that have as their cosmological and, indeed, ontological premise that the universe is only partially illuminated and so social interaction ipso facto occurs in a world that is both unknown and potentially dangerous. As I will show, reciprocal encounters are therefore based on distance rather than approximation. Although people acknowledge the crucial importance of social others, it is equally important to maintain appropriate distances in order to avoid awakening unwanted desires. I will consequently introduce the notion of contrapuntal cosmopolitanism ${ }^{1}$ to designate the production of viable (reciprocal) distances in unfamiliar milieux peopled by important but also capricious others. Before venturing into the ethnographical account, however, let me briefly make some initial remarks on the notion of the stranger in contemporary cosmopolitan writings.

\section{The stranger}

According to Kant, a global cosmopolitan order needs to be founded on a universal law of hospitality allowing us to 'venture out as strangers and sojourn in other territories' (Werbner 2008b: 2). It is thus 'the right of a stranger', Kant says, 'not to be treated with hostility when he arrives on someone else's territory' (1968: 213-16). Within contemporary cosmopolitan studies, Kant's emphasis on transgressing the distinction between stranger and friend continues to hold sway, although emphasis has shifted towards the multiple ways that local agents connect and establish senses of belonging to multiple and only partially known places (Josephides 2003; Werbner 2008a). What I find of particular interest in these recent studies is the ubiquitous emphasis on what Blanche Dubois in Tennessee Williams' play A Streetcar Named Desire calls 'the kindness of strangers'. According to Cheah and Robbins, it is consequently through momentary attachments between strangers in a field that is 'less than kin or friendship but a good deal more than polite or innocent nonrelation' that 'intellectual order and accountability' is introduced in the new world of international civil society (Robbins 1998: 3, 9).

Surely the continuous attempts at carving out supra-local domains capable of establishing momentary equilibria between counteracting social forces have had significant regulatory effects on a global scale. And in this regard, the imagery of the 'kindness of strangers' undoubtedly captures the essence of these political ideals. I remain sceptical, however, whether there is any mileage to be gained from using the concept as an all-embracive analytical trope when exploring different forms of cosmopolitan sensibilities. First, although people everywhere live global lives, in many instances they are coerced to do so by displacement and upheavals. In other words, the very impetus for venturing into unknown territories is based on distance to the familiar rather than approximation towards the new. Such recalcitrant global encounters are perhaps best understood as what Clifford calls 'discrepant cosmopolitanism', which avoids 'the excessive localism of particularist cultural relativism, as well as the overly global vision of a capitalist or technocratic monoculture' (1997: 36). Second, when occupying 'strange lands' (pace Werbner 2008b: 2), recognition of the other is frequently based on hostility rather than hospitality (Fardon 2008: 240). It is thus my contention that although cosmopolitan sensibilities are part and parcel of any social fabric, they 
frequently arise through distance rather than approximation. What we need to explore, then, are the multiple and heterogeneous ways that differently positioned agents produce viable distances in unknown territories by which to engage in potentially beneficial exchanges. Let me therefore now turn to an ethnographic account from Maputo, Mozambique, in order to unfold how relatedness arises through imitation and distantiation. I start out briefly outlining key features of social cosmologies in Southern Mozambique before presenting an extended case study.

\section{Social cosmologies in southern Mozambique}

According to widely shared cosmological beliefs in Southern Mozambique, the archetype for the physical world is a cosmic plane of immanence where all elements exist as pure movement in a chaotic open whole. In order to properly inhabit the physical world and thus extract benefits from disorder, it is consequently of paramount importance to organise the chaos and establish durable distinctions separating the inhabitable from the uninhabitable; order from chaos, e.g. through propitiatory rituals, house-building and everyday cleaning of land (limpeza) (Nielsen 2008: 132-6). Still, despite continuous efforts at manipulating counteracting forces, they might backfire at any moment. All phenomena contain both constructive and destructive potentials and it is always uncertain whether they operate in beneficial or malevolent ways (West 2005: 78, 193; 1996: 25).

When the world is structured by crucial but constantly counteracting forces, social relationships tend to be equally ambiguous. To people in Southern Mozambique, the source of their agency is located outside themselves in their relationships to people and things in the surrounding world. Although the counterpart might at some future point reveal itself to be detrimental, people are essentially what their relations to others make them be, whether this other is a close relative, an inefficient state official or a deceased ancestor still asserting some form of dominance. However, these reciprocal ties might at any time backfire, leaving the initiating agent exposed to the intrusive strategies of others. For many Mozambicans in the Southern region, then, everyday life signifies continuous latent exposures to capricious forces beyond their control. Like the Soweto 'world of witches' so vividly described by Ashforth (2005: 69), life is built on a 'presumption of malice' where one has to assume that anyone with the motive to cause harm will cause harm. Indeed, not everything is known and what is known is that power works in hidden and often capricious ways. Or, put somewhat differently: although chaos is a precondition to order, it constantly threatens to circumvent its momentary equilibrium.

From this admittedly sketchy outline of social cosmologies in Southern Mozambique, let me now turn to an ethnographic case study of how local agents cast in an unstable urban environment manage to produce viable distances to important but potentially malevolent others. I conclude with some remarks on the notion of contrapuntal cosmopolitanism.

\section{The administrator's house}

On 31 October 2001, the Maputo Municipality authorised the demolition of five cement houses in Mulwene, a peri-urban neighbourhood on Maputo's northern periphery. The 
buildings had apparently been erected without proper building permits in an area reserved for an old people's home that was projected to be constructed shortly. A local community chief had informally sold off land within the reserved area and now 22 families were occupying irregular plots while hoping to be allocated formal use rights. According to residents living in the area, the projected construction project would cover less than a third of the reserved area and so they would most likely be allocated use rights to the plots they had been occupying illegally.

In 2000, Mulwene became the centre of public attention when it served as a resettlement zone for the disaster victims after the devastating flooding that hit Mozambique during the first three months of the year. Realising the opportunities for creating a neighbourhood from scratch, the Maputo Municipality soon decided that the hitherto only partially occupied neighbourhood should be a 'model neighbourhood' (bairro modelo), with all the 'requirements that constitute adequate habitation', 2 i.e. stable road network, functional water system and land parcelling in accordance with a fixed set of urban norms according to which legitimate residents would acquire use rights to $15 \times 30$-metre plots on which cement houses should be located 3 metres from the boundary line towards the street. However, given overall administrative weaknesses created through failed socialist schemes after Mozambican independence in 1975, followed by the more recent adoption of neo-liberal economic policies, Mozambique has proved completely incapable of realising such ambitious visions. Thus, newcomers currently access land informally through local chiefs and civil servants who are bribed to parcel out land irrespective of its lack of a legal basis (Nielsen 2007).

The forceful removal of the illegally erected houses seriously affected the sense of security among residents in the area reserved for the old people's home. Fearing that their homes might be demolished, all plans for building cement houses were either postponed or completely abandoned. Despite the insecurities surrounding informal occupancy in the area, however, one impressive building project was initiated. In March 2005, the current administrator in Urban District 3, Victória Ussene, had apparently allocated a huge piece of land informally to the administrator in Marracuene, who wanted to build a house for his mistress. I visited the site shortly afterwards, and it was indeed apparent that a construction project had been started. Sacks of cement were piled up and several local bricklayers were busy mixing sand and cement while erecting the first layers of a fence to surround what was at least a $30 \times 30$-metre plot. Shortly afterwards, the area was inspected by the local community chief and an architect, who registered all residents and measured the section of the area already inhabited. During the next two weekends, they parcelled out two blocks consisting of 16 plots $(15 \times 30$ metres each), which were subsequently allocated to the residents who had previously occupied irregular pieces of land in the area.

\section{Interlude: the production of distance}

Before proceeding with the empirical account, we need to make a brief analytical digression in order to properly unfold key components of what I initially defined as contrapuntal cosmopolitanism. Let me start with Werbner's succinct statement that 'cosmopolitans insist on the human capacity to imagine the world from an Other's perspective and to imagine the possibility of a borderless world of cultural plurality' 
(2008b: 2). In this sense, a cosmopolitan perspective is a way of coming to terms with difference in contexts of diversity; and, as I will argue, this is particularly so in relation to contrapuntal others. Seeing the world from an Other's perspective obviously entails an imaginary point of view from where one's own position is visible and, equally important, exterior in relation to the former. There is, so to speak, a quantitative distance between self and other, who remain outside and thus irreducible to each other in order for reciprocal exchanges to occur. If we take as a premise that any distance implies two end-points, or positions if you like, between which there can be established series of exchanges with unique rhythms and velocities, it logically follows that one's capacities to act are coextensive with the distance produced between self and other. In a nutshell, the individual positions - or perspectives - are produced by the distance between them rather than vice-versa. This is essentially what I take to be the key feature of contrapuntal cosmopolitanism and in order to substantiate this idea, let me once more return to the socio-cultural universe in Mulwene. As I will argue, informal house-building projects can be seen as a particular form of contrapuntal cosmopolitanism that produces viable (reciprocal) distances in an unfamiliar milieu peopled by important but also capricious others.

\section{Standing in the shadow of power}

I visited the area originally reserved for the old people's home in June 2005, when the architect and the community leader were about to complete the parcelling out of the two blocks. Outside the administrator's building site, I met Reugénio, his nearby neighbour, who was living in a two-room reed-hut with his wife and three children while saving up money to build a cement house. 'We're not worried anymore', Reugénio assured me with a smile. 'With the administrator here, they can't throw us out. Now, we want to build real houses as well'. Indeed, during the coming months, residents in the area commenced building projects in the plots parcelled out by the architect and the community chief. As Reugénio later explained, although the presence of the district administrator from Marracuene was considered as a potential threat to their continued occupancy, his construction project also cast a legitimising light on their hitherto informal settlement. The building project was undoubtedly 'on the margins of the law', as Reugénio eloquently put it, but it indicated how secure occupancy might be achieved. Hence, it was Reugénio and a small group of residents who contacted the architect through a local community leader and paid him to parcel out the area so that the two blocks were laid out in alignment with the district administrator's plot. According to state and municipal agents, the informal parcelling-out of the area did, in fact, transform the status of the residents. Whereas previously they were considered as illegal squatters who could be removed with force, they were now defined as potentially legitimate residents. As the head of the urbanisation department at the Maputo Municipality argued, if people were occupying parcelled-out plots adjacent to an administrator's building site, they had to be legitimate residents. Furthermore, considering the lacking administrative capacities, informal occupancy in Mulwene was frequently legitimised provided it adhered to the urban ideals associated with the initial aspirations of creating a 'model neighbourhood', i.e. cement houses located 3 metres from plot limits in $15 \times 30$-metre parcelled-out plots. We might therefore argue that 
the parcelling-out of the area near the administrator's house established an appropriate distance to potentially malignant others. Seeing themselves from the perspective of the state, Reugénio and his fellow residents knew that the only way of creating a secure future in an unstable social environment would be to align themselves with those forces (i.e. the administrator's building project) which were equally desirable and dangerous. Put somewhat differently, by parcelling out the area, the residents were making themselves visible in order to disappear in the eyes of an erratic other without which social existence in the city would be impossible.

\section{Contrapuntal cosmopolitanism}

If, as Beck argues, a cosmopolitan perspective is grounded in a negotiation of and with otherness (2002), then, surely, this must include elements of 'reflexive selfdistantiation' (Werbner 2008b: 18), whereby individual agents momentarily seek to position themselves as their primary contrapuntal other. Through this perspectival displacement between self and other, a social distance emerges that demarcates, so to speak, the scope for reciprocal interactions. In this regard, I find Robbins' argument that 'actually existing cosmopolitanism is a reality of (re)attachment, multiple attachment, or attachment at a distance' (1998: 3) particularly pertinent. In this article I have thus been guided by the idea of seeing cosmopolitanism as attachment at a distance. I have argued that the idea of the 'kindness of strangers' has limited analytical purchase when studying local cosmopolitan encounters. Rather than focusing on social approximation, I have suggested that we explore how people distance themselves from others and through that distance establish viable reciprocal relationships. As I have furthermore outlined through the empirical case study, this approach is particularly appropriate when exploring social life in unknown milieux, peopled by potentially malevolent strangers, such as district administrators and local community chiefs. Indeed, in Mulwene, house-building activities can be seen as creative attempts at producing viable distances in a partially illuminated socio-cultural universe where capricious forces constantly threaten to circumvent any momentary equilibrium. To paraphrase Corsín Jimenez, house-building is here 'a matter of finding the right balance between the visible and the invisible elements of social life' (2008: 180), which will hopefully open towards reciprocal exchanges with important but also potentially dangerous others. When the group of informal residents consolidated their occupancy by contracting an architect to parcel out the area, they were not merely imitating the workings of power. Rather, they were communicating in a widely shared aesthetic language in an attempt to enforce on a recalcitrant world the need to recognise their position as unique but also at a viable distance from important others. As a reflection of what I have called contrapuntal cosmopolitanism, it is a kind of perspectival displacement where the individual agent makes him- or herself available in a form that can be recognised by the other. In order for an agent to elicit an effect from an Other, he or she must consequently manifest themselves in particular concrete ways (Strathern 1999: 259) and in the socio-cultural environment in Mulwene, this is equivalent to building cement houses in parcelled-out plots. Contrapuntal cosmopolitanism is thus about finding the appropriate distance to capricious others through ideational, communicative and physical media so that reciprocal exchanges can be realised without simultaneously 
being attacked by malevolent or greedy counterparts. Although highly volatile and exposed to shifting socio-political agendas, it is through such forms of contrapuntal cosmopolitanism that people living on the fringes of Mozambican society manage to engage with important but also capricious others in unfamiliar social milieux.

\author{
Morten Nielsen \\ Department of Anthropology, Archaeology and Linguistics \\ University of Aarbus \\ Jens Chr. Skous Vej 3 \\ DK-8000 Aarbus C \\ etnomn@bum.au.dk
}

\title{
References
}

Ashforth, A. 2005. Witchcraft, violence and democracy in South Africa. Chicago, IL: University of Chicago Press.

Beck, U. 2002. 'The cosmopolitan society and its enemies', Theory, Culture and Society 19: 17-44.

Cheah, P. 2006. 'Cosmopolitanism', Theory, Culture and Society 23: 486-96.

Clifford, J. 1997. Routes: travel and translation in the late twentieth century. Cambridge, MA: Harvard University Press.

Corsín Jiménez, A. 2008. Well-being in anthropological balance: remarks on proportionality as political imagination, in A. C. Jiménez (ed.), Culture and well-being. anthropological approaches to freedom and political ethics, 180-97. London: Pluto Press.

Diderot, D. and J. L. R. d'Alembert 1751-65. Encyclopédie ou dictionnaire raisonné des sciences, des arts, et des métiers. Paris: Briasson, David, Le Breton, Durand.

Fardon, R. 2008. Cosmopolitan nations, national cosmopolitans, in P. Werbner (ed.), Anthropology and the new cosmopolitanism. rooted, feminist and vernacular perspectives, 233-59. Oxford: Berg.

Josephides, L. 2003. The rights of being human in a global world, in R. Wilson and J. Mitchell (eds.), Human rights in global perspective, 229-50. London: Routledge.

Kant, I. 1968. Zum ewigen Frieden. Ein philosophischer Etnwurf, in W. Weischedel (ed.), Werkausgabe $X I, 195-228$. Frankfurt am Main, Suhrkamp.

Nielsen, M. 2007. Shifting registers of leadership. an ethnographic critique of the unequivocal legitimization of commmunity authorities, in L. Buur, H. Kyed and T. C. d. Silva (eds.), State recognition of local authorities and public participation: experiences, obstacles and possibilities in Mozambique, 159-76. Maputo: Ministério da Justica/Centro de Formacão Juridica e Judiciária.

Nielsen, M. 2008. In the vicinity of the state. House construction, personhood, and the state in Maputo, Mozambique. PhD dissertation, Department of Anthropology, University of Copenhagen.

Rapport, N. 2006. 'Anthropology as cosmopolitan study', Antbropology Today 22: 23-24.

Robbins, B. 1998. Actually existing cosmopolitanism, in P. Cheah and B. Robbins (eds.), Cosmopolitics: thinking and feeling beyond the nation, 1-19. Minneapolis, MN: University of Minnesota.

Strathern, M. 1999. Property, substance and effect. Anthropological essays and persons and things. London: The Athlone Press.

Werbner, P. 2008a. The cosmopolitan encounter: social anthropology and the kindness of strangers, in P. Werbner (ed.), Anthropology and the new cosmopolitanism. Rooted, feminist and vernacular perspectives, 47-68. Oxford: Berg.

Werbner, P. 2008b. Introduction: towards a new cosmopolitan anthropology, in P. Werbner (ed.), Anthropology and the new cosmopolitanism. Rooted, feminist and vernacular perspectives, 1-29. Oxford: Berg.

West, H. G. 1996. 'Creative destruction and sorcery of construction: power, hope and suspicion in post-war Mozambique’, Polar 20: 13-31.

West, H. G. 2005. Kupilikula. Governance and the invisible realm in Mozambique. Chicago, IL: University of Chicago Press. 